\title{
SOCRATES 3 (synopsis of Cochrane reviews applicable to emergency services)
}

\author{
P Gilligan, H Law, G Lumsden, J Brenchley, G Kitching, A Taylor, A Khan, M Shepherd, J Jones, \\ D Hegarty
}

\begin{abstract}
"Employ your time in improving yourself by other men's writings so that you should come easily by what others have laboured hard for". Socrates (399-469 BC)
\end{abstract}

n this the third article of the SOCRATES series the working party present summaries of the output of the Cochrane Collaborative Review Groups who indeed "have laboured hard" and to whom all of those interested in the practice of evidence based medicine owe a debt of gratitude.

The quality of systematic reviews from the Cochrane Library has been shown to be consistently of a high standard. ${ }^{2}$ Emond et al felt that $12 \%$ of the 795 completed reviews in the Cochrane Database of Systematic Reviews (CDSR) from April 2000 were directly relevant to emergency medicine and that more than one third of the CDSR had some relevance to their practice. ${ }^{3}$ Rowe et al argued that "given the high quality of the Cochrane Reviews, it would seem reasonable to expect Emergency Physicians to become familiar with this systematic review resource". ${ }^{4}$ The SOCRATES group was formed independently to find and summarise those completed reviews that our fellow practitioners should be most familiar with.

As noted previously the SOCRATES group examined 1750 articles in the CDSR that had been produced by 52 review groups and summarised the articles that they deemed to be particularly relevant to those practising emergency medicine. This article presents summaries of relevant reviews in the areas of respiratory medicine.

\section{Methodology}

The members of the 10 strong SOCRATES team were assigned Cochrane groups whose articles were of particular interest to them. A pair of reviewers then selected the articles from each of the Cochrane Groups that they felt were relevant to emergency medicine. In the event of disagreement the lead author decided on the appropriateness of a paper for inclusion. A reviewer then summarised the article using a format that had previously been agreed by the team. Each review was presented to the group. The full text of the article was then given to another group member and the accuracy of the synopsis assessed. Only completed reviews were considered for summarising as protocols (reviews in preparation) could not be used to give a definitive answer.

The structure of each synopsis is as follows:

- Title

- Background-information about the condition and question addressed by the review.

- Results-number of studies, number of patients.

- SOCRATES says-the answer to the clinically relevant question where available.

- Authors of the Cochrane review

The summaries were then grouped under various headings.

\section{INHALED CORTICOSTEROIDS IN ACUTE ASTHMA AFTER EMERGENCY DEPARTMENT DISCHARGE}

Patients discharged from the emergency department after exacerbations of their asthma are commonly treated with inhaled $\beta_{2}$ agonist and short courses of oral corticosteroids (CS). The role of inhaled corticosteroids (ICS) in addition to, or instead of CS may have beneficial effects with respect to preventing relapses or development of side effects.

\section{Results}

Ten trials were included for evaluation. Three of these (involving 909 patients) compared ICS and CS versus CS alone, and found no statistically significant benefit. Seven trials (involving 1204 patients) compared high dose ICS versus CS alone, and found no significant differences between either group with respect to relapse, $\beta_{2}$ agonist use, symptoms, or adverse effects. However, the sample size was inadequate to exclude the possibility of either treatment being inferior and severe asthmatic patients were excluded from these trials.

\section{SOCRATES says}

Current evidence does not support the addition of ICS to oral CS or as a replacement for oral CS in the management of asthmatic patients discharged from the ED.

A Edmonds ML, Camargo CA Jr, Brenner BE, et al. Inhaled steroids in acute asthma following emergency department discharge. Cochrane Library. Issue 1. Oxford: Update Software, 2001.

\section{MAGNESIUM SULPHATE FOR TREATING EXACERBATIONS OF ACUTE ASTHMA IN THE EMERGENCY DEPARTMENT}

The treatment of acute asthma in the emergency department (ED) entails the reversal of bronchospasm and initiation of measures to reduce airway inflammation. Conventional agents for bronchodilatation include the $\beta_{2}$ agonists, anticholinergic agents, and phosphodiesterase inhibitors. There is some evidence that magnesium sulphate $\left(\mathrm{MgSO}_{4}\right)$ may confer additional bronchodilating effects.

\section{Results}

Seven trials were included for evaluation, involving 665 patients. The $\mathrm{MgSO}_{4}$ regimens used were $2 \mathrm{~g}$ intravenously over 20 minutes for adults, between $25-100 \mathrm{mg} / \mathrm{kg}$ over 20 minutes in children. There were no statistically significant improvements in peak expiratory flow rates and admission to hospital when all studies were pooled. However, in those patients studied with acute severe asthma (defined as PEFR $<25-30 \%$ predicted after one nebuliser (adults), nonresponse to treatment (adult or children), or PEFR $<60 \%$ predicted (children), there was a statistically (and clinically) significant improvement in both PEFR and forced expiratory volume in one second $\left(\mathrm{FEV}_{1}\right)$ along with reduction in 
hospital admissions. There were no recorded changes in pulse or blood pressure.

\section{SOCRATES says}

The current evidence does not support the routine use of $\mathrm{MgSO}_{4}$ for all patients presenting to the ED with exacerbations of their asthma. However, in those patients with acute severe asthma, the addition of $\mathrm{MgSO}_{4}$ to the usual bronchodilatation regimen seems to be both safe and beneficial.

$\Delta$ Rowe BH, Bretzlaff JA, Bourdon C, et al. Magnesium sulfate for treating exacerbations of acute asthma in the emergency department. Cochrane Library. Issue 4. Oxford: Update Software, 2000.

\section{HOLDING CHAMBERS COMPARED WITH NEBULISERS FOR $\beta$ AGONIST TREATMENT OF ACUTE ASTHMA}

The mainstay of treatment of acute asthma entails the administration of rapid acting bronchodilating agents, most commonly the $\beta_{2}$ agonists. These are typically delivered through a nebulising device. The efficacy of the delivery of $\beta_{2}$ agents via metered dose inhaler and spacer is evaluated in this review.

\section{Results}

Sixteen randomised controlled trials comparing $\beta_{2}$ agonist via holding chamber compared with nebulisation for the exacerbations of asthma were included in the review (686 children and 375 adults). The method of $\beta_{2}$ delivery did not seem to affect hospital admission rates. The duration of emergency department stay was significantly shorter in children when treated with the holding device compared with the nebuliser. The length of stay for adults was similar for both methods.

\section{SOCRATES says}

The current evidence suggests that the use of a holding device may be a viable alternative to nebulisation in the delivery of $\beta_{2}$ agonists, particularly in children.

$\Delta$ Cates CJ, Rowe BH. Holding chambers versus nebulisers for beta-agonist treatment of acute asthma. Cochrane Library. Issue 4. Oxford: Update Software, 2000.

\section{COMBINED INHALED ANTICHOLINERGICS AND $\beta_{2}$ AGONISTS FOR THE INITIAL TREATMENT OF ACUTE ASTHMA IN CHILDREN}

The efficacy of the addition of anticholinergic agents to the standard $\beta_{2}$ agonist agents is evaluated by this review.

\section{Results}

Thirteen randomised controlled trials comparing a combination of inhaled anticholinergics and $\beta_{2}$ agonists with $\beta_{2}$ agonists alone in children aged 18 months to 17 years were included in this review. The addition of a single dose of anticholinergic agent to $\beta_{2}$ agonist treatment did not reduce hospital admission, but did lead to a significant improvement in lung function at 60 and 120 minutes. The addition of multiple doses of anticholinergic agents to $\beta_{2}$ agonist agents resulted in $25 \%$ reduction in hospital admissions in children with moderate to severe exacerbations. There was no difference in side effects with combined anticholinergic and $\beta_{2}$ agonist treatment compared with $\beta_{2}$ agonist alone.

\section{SOCRATES says}

The addition of multiple doses of anticholinergic agents to $\beta_{2}$ agonist agents is safe, results in an improvement in lung function, and may lead to a reduction in hospitalisation rates in patients with "severe" exacerbations.
A Plotnick LH, Ducharme FM. Combined inhaled anticholinergics and beta 2agonists for initial treatment of acute asthma in children. Cochrane Library. Issue 4. Oxford: Update Software, 2000.

\section{CORTICOSTEROIDS FOR PREVENTING RELAPSE AFTER ACUTE EXACERBATIONS OF ASTHMA}

The role of a short course of glucocorticoids at the time of discharge on the prevention of subsequent relapses of asthma is evaluated in this review.

\section{Results}

Seven randomised controlled trials dealing with the outpatient treatment of asthma exacerbations using glucocorticoids at discharge and reporting relapse rates or pulmonary function tests (PFTs) were included in this review. In five of these, glucocorticoids were given orally, in the remaining two, intramuscularly. Significantly fewer patients receiving glucocorticoids relapsed in the first week necessitating additional care, an effect that was maintained over the first 21 days. In addition, the glucocorticoid treated patients used less $\beta$ agonists. There were no differences in PFTs in those studies reporting these outcome measures at follow up.

\section{SOCRATES says}

The current evidence suggests that a short course of glucocorticoids after initial assessment for an acute exacerbation of asthma results in a significant reduction in relapse to the need for additional care at 7 to 10 days and a reduction in the use of $\beta$ agonists. Both the intramuscular and oral routes seem to be equally efficacious.

A Rowe BH, Spooner C, Ducharme FM, et al. Corticosteroids for preventing relapse following acute exacerbations of asthma. Cochrane Library. Issue 4. Oxford: Update Software, 2000

\section{ADDITION OF INTRAVENOUS AMINOPHYLLINE TO $\beta_{2}$ AGONISTS IN ADULTS WITH ACUTE ASTHMA}

The methylxanthines (aminophylline and theophylline ) have been used in the treatment of asthma for many years, but there remains debate regarding their efficacy in this setting.

\section{Results}

A total of 15 randomised controlled trials comparing intravenous aminophylline and placebo in adults with acute exacerbations of asthma treated in the emergency setting were included. No statistically significant effect of aminophylline on airflow measurement was recorded at any time, although there was a moderate clinical improvement. Subgroup analysis according to the initial severity of the asthma also failed to show any statistically significant effect. There was no difference in the rate of hospital admissions. Patients treated with aminophylline reported more palpitations and arrhythmias and vomiting than in the placebo group.

\section{SOCRATES says}

The current evidence does not support the use of aminophylline in the treatment of adults with acute asthma.

A Parameswaran K, Belda J, Rowe BH. Addition of intravenous aminophylline to beta 2 -agonists in adults with acute asthma. Cochrane Library. Issue 4. Oxford: Update Software, 2000

\section{EARLY EMERGENCY DEPARTMENT TREATMENT OF ACUTE ASTHMA WITH SYSTEMIC CORTICOSTEROIDS}

The timing of the administration of corticosteroids in the emergency treatment of asthma is a matter of ongoing debate. 


\section{Results}

Twelve randomised or quasi-randomised trials were included in the review. Studies were included if patients presenting to the emergency department with acute asthma were treated with corticosteroids (intravenously/intramuscularly/orally) compared with placebo within one hour of arrival and either pulmonary function results or admission rates were reported The early use of corticosteroids resulted in a significant reduction in the number of admissions, especially in those patients not receiving corticosteroids before emergency presentation and in those whose asthma was deemed to be more severe at the time of initial assessment.

\section{SOCRATES says}

The current evidence supports the early use of corticosteroids (within one hour) in the treatment of patients with acute asthma in the emergency setting.

A Rowe BH, Spooner C, Ducharme FM, et al. Early emergency department treatment of acute asthma with systemic corticosteroids. Cochrane Library. Issue 4. Oxford: Update Software, 2000.

\section{CONCLUSION}

We hope that this synopsis of the Cochrane reviews applicable to emergency services will help to disseminate some of the important information in the Cochrane Database of Systematic Reviews and continue to inform the evolving practice of evidence based emergency medicine.

\section{ACKNOWLEDGEMENTS}

We would like to thank Dr Richard Hardern and the staff of the Postgraduate Medical Library at the General Infirmary at Leeds for their support and technical advice in the preparation of this paper.

\section{Authors' affiliations}

P Gilligan, H Law, G Lumsden, J Brenchley, G Kitching, A Taylor,

A Khan, M Shepherd, J Jones, Specialist Registrars in Emergency

Medicine on The Yorkshire Rotation, UK

D Hegarty, General Practitioner, Leeds, UK

Funding: none.

Conflicts of interests: none declared.

Correspondence to: Dr P Gilligan, 1 Far Moss, Alwoodley, Leeds LS17 7NU, UK; hegartydeirdre@ireland.com

\section{REFERENCES}

1 Jadad AR, Moher M, Browman GP, et al. Systematic reviews and meta-analyses on treatment of asthma: critical evaluation. $B M J$ 2000;320:537-40.

2 Olssen O, Middleton P, Ezzo J, et al. Quality of Cochrane reviews: assessment of sample from 1998. BMJ 2001;323:829-32.

3 Emond SE, Wyer PC, Brown MD, et al. How relevant are the systematic reviews in the Cochrane Library to emergency medical practice? Ann Emerg Med 2002;39:153-8.

4 Rowe BH, Wyer PC, Cordell WH. Improving the dissemination of systematic reviews in emergency medicine. Ann Emerg Med 2002;39:293-5. 